Quim. Nova, Vol. 35, No. 7, 1464-1467, 2012

\title{
APPLICATION OF FTIR IN THE DETERMINATION OF ACRYLATE CONTENT IN POLY(SODIUM ACRYLATE- CO-ACRYLAMIDE) SUPERABSORBENT HYDROGELS
}

\author{
Antônio Sávio G. Magalhães \\ Curso de Química, Faculdade de Educação de Itapipoca, Universidade Estadual do Ceará, 62500-000 Itapipoca - CE, Brasil \\ Manuel P. Almeida Neto \\ Instituto Federal de Educação, Ciência e Tecnologia do Rio Grande do Norte, Campus Caicó, 59300-000 Caicó - RN, Brasil \\ Maslândia N. Bezerra, Nágila M. P. S. Ricardo e Judith P. A. Feitosa* \\ Departamento de Química Orgânica e Inorgânica, Universidade Federal do Ceará, CP 6021, 60455-760 Fortaleza - CE, Brasil
}

Recebido em 25/11/11; aceito em 30/1/12; publicado na web em 15/6/12

\begin{abstract}
Hydrogels have been prepared by free-radical solution copolymerization of acrylamide and sodium acrylate (NaAc), with molar ratio ranging from $25 / 75$ to $80 / 20$, respectively, using methylene bisacrylamide as the crosslinking agent. A FTIR spectroscopy procedure to determine the acrylate/acrylamide ratio in these hydrogels was proposed based on absorbance at $1410 \mathrm{~cm}^{-1}\left(\mathrm{vCOO}^{-}\right)$and 2940 $\mathrm{cm}^{-1}\left(\mathrm{vCH}\right.$ and $\left.\mathrm{vCH}_{2}\right)$. A straight line with a good linear correlation coefficient $(0.998)$ was obtained by plotting the acrylate content (Ac\%) versus relative absorbance $\left(\mathrm{A}_{\mathrm{rel}}=\mathrm{A}_{1410} / \mathrm{A}_{2940}\right)$. Results were confirmed by the amount of sodium cation released in acid medium determined by atomic absorption spectrometry.
\end{abstract}

Keywords: hydrogel; sodium acrylate; FTIR.

\section{INTRODUCTION}

Anionic superabsorbent hydrogels based on acrylic acid (HAc) or sodium acrylate $(\mathrm{NaAc})$ and acrylamide $(\mathrm{Am})$ are well known, extensively studied and produced on a large scale. ${ }^{1}$ Hydrogels can swell to absorb huge volumes of water or aqueous solution and are widely employed in sanitary applications, such as diapers and tampons and as a soil conditioner in agriculture for retaining soil moisture in arid areas. Despite being in use for a long period, interest in these hydrogels remains, as can be seen in Table 1.

Table 1. Recent studies of hydrogels based on acrylic acid/sodium acrylate and acrylamide (Am)

\begin{tabular}{cccc}
\hline mol\% of Am & Crosslinker & Study & Ref. \\
\hline $0-100$ & MBA & Bulk stream potential & 2 \\
14 & MBA & Cu(II), Fe(III) removal & 3 \\
38.6 & MBA & Ni(II) removal & 4 \\
75 & MBA & Drug delivery & 5 \\
$70.9-92.7$ & MBA & pH effect & 6 \\
24,5 & Various & Crosslinker effect & 7 \\
$25 ; 50 ; 75$ & EGDM & Cu(II) removal & 8 \\
$15 ; 20 ; 30$ & g-radiation & Dyes removal & 9 \\
$30-70$ & g-radiation & Characterization & 10 \\
\hline
\end{tabular}

$\overline{\mathrm{MBA}}=\mathrm{N}, \mathrm{N}$-methylene bisacrylamide; $\mathrm{EGDM}=$ ethylene glycol dimethacrylate

There is also interest in composites of poly(acrylamide-co-acrylate) and clays (hydrotalcite, ${ }^{11}$ bentonite), ${ }^{12}$ composites with rice husk ash $^{13}$ and grafts with polysaccharides ( $\operatorname{starch},{ }^{14}$ carboxymethyl-cellulose, ${ }^{15}$ cashew gum ${ }^{16}$ ).

Hydrogels based on acrylate and acrylamide can be synthesized in different ways: a) mixture of acrylamide and acrylate; ${ }^{4,12}$ b) acrylamide plus acrylic acid followed by neutralization with $\mathrm{NaOH} ; 3^{3,7,10}$

*e-mail: judith@dqoi.ufc.br c) hydrolysis of acrylamide gel with $\mathrm{NaOH} ; ;^{17,18}$ and hydrolysis of polyacrylonitrile with $\mathrm{NaOH} .{ }^{14}$ All hydrogels, except those obtained by method "a", will need a definition of the precise amount of ionic charge. Even in this method, the real ratio of monomeric units can change because, depending on their origin, monomers contain different amounts and kinds of stabilizer agents, not always eliminated from starting materials.

Elemental analysis was the only method cited in the literature for determining degree of hydrolysis of polyacrylamide hydroge ${ }^{18}$ and amount of acrylamide in poly(HAc-co-Am) hydrogel..$^{8,10}$ In both cases, carbon and nitrogen percentages are those employed in the calculation. Nitrogen is an element from acrylamide while carbon is from all the monomers (acrylamide and acrylic acid or acrylate) and also from the cross-linking agent. The $\mathrm{C} \% / \mathrm{N} \%$ ratios measured in poly(HAc-co-Am) hydrogels were significantly different from the theoretical values. ${ }^{8}$ For example, the $\mathrm{C} \% / \mathrm{N} \%$ theoretical value for a hydrogel with 75:25 HAc:Am was 8.54 versus the experimental value of $10.44 .^{8}$

Fourier transform infrared (FTIR) spectroscopy is one of the most widely employed techniques for analyzing polymeric materials. ${ }^{19}$ It is a suitable tool to characterize crosslinked materials, such as hydrogels, taking into account that it is not necessary to dissolve the material, and in this case, impossible to achieve in a non-destructive way. For hydrogels based on acrylic acid or acrylate and acrylamide, FTIR has been used to: confirm the presence of monomers and crosslinker in the copolymer chemical structure $;^{5,12,14,15}$ to verify the partial neutralization of acrylic acid monomer; ${ }^{10}$ to corroborate intercalation onto silicate layers $;{ }^{11}$ and to investigate intermolecular interaction between metal ions and hydrogel functional groups. ${ }^{3,8}$ The degree of hydrolysis of polyacrylamide hydrogels was also roughly calculated by FTIR spectroscopy. ${ }^{18}$

Since ionic content is one of the most important parameters that affect swelling, knowledge of the real acrylamide/acrylate ratio in these hydrogels is a subject of interest. The aim of the present work was to report a procedure to determine acrylate/acrylamide ratio in poly(sodium acrylate- $c o$-acrylamide) hydrogels, based on the widely used spectroscopic technique of FTIR. 


\section{EXPERIMENTAL}

\section{Materials}

Acrylamide (Am), acrylic acid, potassium persulfate (KPS) and $\mathrm{N}, \mathrm{N}, \mathrm{N}^{\prime}, \mathrm{N}^{\prime}$-tetramethylethylenediamine (TEMED) were obtained from Merck. N,N'-methylene bisacrylamide (MBA) was purchased from Sigma. Sodium acrylate $(\mathrm{NaAc})$ was prepared by neutralization of acrylic acid with $\mathrm{NaOH}$, up to $\mathrm{pH} 7.0$ in an ice bath. ${ }^{20}$ A solution at $3 \mathrm{~mol} / \mathrm{L}$ concentration was obtained for further utilization. All materials were used as received. Distilled water was used throughout all experiments.

\section{Hydrogel synthesis}

Hydrogels were synthesized by free-radical copolymerization, following the method of Okay et al. ${ }^{21}$ and Jeon et al. ${ }^{22}$ with slight modifications while keeping the quantity of MBA, KPS and TEMED at a constant value of $0.5,0.1$ and $0.1 \mathrm{~mol} \%$, respectively, based on the total quantity of monomer. Gels were prepared, with molar ratio of Am to NaAc ranging from $0 / 100$ to $100 / 0$.

All gels were prepared as follows: an adequate volume of $3 \mathrm{~mol} / \mathrm{L}$ Am freshly prepared aqueous solution, MBA $(7.6 \mathrm{~mL}$ at $0.1 \mathrm{~mol} / \mathrm{L})$ and KPS $(1.52 \mathrm{~mL}$ at $0.1 \mathrm{~mol} / \mathrm{L})$ were added to an adequate volume of $3 \mathrm{~mol} / \mathrm{L}$ aqueous $\mathrm{NaA}$. The total volume of monomers solutions was kept at $50.0 \mathrm{~mL}$. More specifically, the volumes of $\mathrm{Am}$ and $\mathrm{NaAc}$ solutions for the preparation of Gel (25/75) were 12.5 and $37.5 \mathrm{~mL}$, respectively. The system was kept under stirring until complete dissolution of species. The volume was increased to $50 \mathrm{~mL}$ with distilled water. Nitrogen was bubbled through for $10 \mathrm{~min}$ followed by the addition of $0.57 \mathrm{~mol} / \mathrm{L}$ TEMED $(250 \mu \mathrm{L})$. The system was kept under further stirring until reaching the gelling point, defined as when the magnetic bar could no longer stir.

After $24 \mathrm{~h}$ rest, the material was grated, washed several times with a mixture of ethanol:water at the proportion of $2: 1$ by volume and dried in an oven at $70{ }^{\circ} \mathrm{C}$. The material was sieved in order to obtain samples with particles sizes in the range of 100 to $240 \mu \mathrm{m}$ (9 to 24 mesh).

\section{Infrared spectroscopy studies}

The Fourier transform IR spectra (FT-IR) of dried gels were recorded with a Shimadzu IR spectrophotometer (model 8300) in the range of 400 and $4000 \mathrm{~cm}^{-1}$ as a $\mathrm{KBr}$ pellet. In order to determine the real ratio of $\mathrm{NaAc} / \mathrm{Am}$, homopolymers of acrylamide and sodium acrylate were synthesized, without addition of the crosslinked agent. FT-IR spectra of mixtures of PAm and PNaAc at a mol ratio similar to that of hydrogels were also recorded.

\section{Atomic absorption spectrometry}

A sample of around $50 \mathrm{mg}$ of hydrogel containing copolymer of $50 \%$ of both Am and $\mathrm{NaAc}(\mathrm{Gel} 50 / 50)$ was immersed in $100 \mathrm{~mL}$ of distilled water at room temperature $\left(25-27^{\circ} \mathrm{C}\right)$ for 10 days to assure equilibrium was reached. An aliquot of the outside solution was analyzed by atomic absorption spectrometry on a Varian spectrophotometer model Spectra A 55 to quantify sodium ion present. The same procedure was adopted with the immersion of the hydrogel in $\mathrm{HCl}$ at $\mathrm{pH} 2$ (after the equilibrium in water was reached).

\section{Swelling}

A known mass of purified hydrogel in the range of 30-50 mg was placed inside a pre-weighed sintered glass filter $\left(\mathrm{n}^{\circ} 0\right)$ and covered with distilled water at room temperature $\left(31 \pm 1{ }^{\circ} \mathrm{C}\right)$ until swelling equilibrium was reached. The glass filter was then removed from the water, and excess water drained by gravity for a few minutes. The external and internal contained walls not in contact with the gel were dried and the system re-weighed.

The degree of swelling equilibrium $\left(W_{\text {eq }}\right)$ was determined by Equation 1:

$$
W_{\mathrm{eq}}=\frac{m_{\mathrm{sw}}-m_{\mathrm{dr}}}{m_{\mathrm{dr}}}
$$

where $m_{\mathrm{sw}}$ and $m_{\mathrm{dr}}$ are the masses of swollen and dry polymer, respectively. All swelling experiments were repeated at least three times.

\section{RESULTS AND DISCUSSION}

\section{FT-IR analysis}

The spectra of Gel (50/50), homopolymeric Gel (Am) and Gel $(\mathrm{NaAc})$ are depicted in Figure 1. Table 2 lists the attribution of the main bands. ${ }^{23}$ As expected, the Gel (50/50) spectrum is composed of bands from Gel (Am) and Gel (NaAc). The bands at 3410-3421 $\mathrm{cm}^{-1}$ $\left(v_{\text {as }} \mathrm{NH}_{2}\right), 3190-3194 \mathrm{~cm}^{-1}\left(\mathrm{v}_{\mathrm{s}} \mathrm{NH}_{2}\right)$ and $1682-1685 \mathrm{~cm}^{-1}(\mathrm{n} \mathrm{C}=\mathrm{O})$ are characteristics of the acrylamide unit. Bands at 1560 and 1406-1410 $\mathrm{cm}^{-1}$ are due to carboxylate group stretching of acrylate. The presence of a weak band at $1710 \mathrm{~cm}^{-1}$ in $\mathrm{Gel}(\mathrm{NaAc})$ indicates a small fraction of the $\mathrm{COOH}$ group not totally neutralized in the first step of synthesis. The shoulder in the same region also suggests the presence of $\mathrm{COOH}$ in the copolymer hydrogel. The presence of adsorbed water can be seen by the band at $3300 \mathrm{~cm}^{-1}$ in all spectra. At $1653-1654 \mathrm{~cm}^{-1}$, a stretching of the $\mathrm{C}=\mathrm{O}$ group from the acrylamide unit appears in $\mathrm{Gel}$ (Am) and Gel (50/50) spectra. At this wavenumber there is also the $\mathrm{OH}$ angular deformation from water, which explains the existence of this band in the polyacrylate spectrum. The stretching vibrations of carboxylate of the acrylate unit and $\mathrm{CN}$ from acrylamide unit are superposed at $1406-1410 \mathrm{~cm}^{-1}$.

The first step of the method was the synthesis of polyacrylamide (PAm) and poly(sodium acrylate) homopolymers. Spectra of PAm, $\mathrm{PNaAc}$ and a mixture of two, were obtained in a $\mathrm{KBr}$ pellet. The mixture was done in order to obtain mol\% of acrylate, in relation to



Figure 1. FT-IR spectra of hydrogel of: (A) polyacrylamide; (B) poly (sodium acrylate-co-acrylamide) 50/50 and (C) poly(sodium acrylate), all gels crosslinked with MBA 
Table 2. Attribution of main bands in FTIR spectra of Gel(Am), Gel(50/50) and $\mathrm{Gel}(\mathrm{NaAc})$

\begin{tabular}{|c|c|c|c|}
\hline \multicolumn{3}{|c|}{ Hydrogel } & \multirow{2}{*}{ Assignment $^{23}$} \\
\hline $\operatorname{Gel}(\mathrm{Am})$ & $\operatorname{Gel}(50 / 50)$ & $\mathrm{Gel}(\mathrm{NaAc})$ & \\
\hline 3410 & 3421 & - & $v_{\text {as }} \mathrm{NH}_{2}$ of acrylamide unit \\
\hline 3300 & 3300 & 3300 & $\checkmark \mathrm{OH}$ of adsorbed water \\
\hline 3190 & 3194 & & vs $\mathrm{NH}_{2}$ of acrylamide unit \\
\hline 2931,2860 & 2941,2860 & 2944,2860 & $v \mathrm{CH}$ and $v \mathrm{CH}_{2}$ \\
\hline- & - & 1710 & $\vee \mathrm{C}=\mathrm{O}$ of acrylic acid \\
\hline 1685 & 1682 & - & $v \mathrm{C}=\mathrm{O}$ of acrylamide \\
\hline 1654 & 1654 & 1653 & $\begin{array}{c}\mathrm{vC}=\mathrm{O} \text { of acrylamide and } \delta \mathrm{OH} \text { of } \\
\text { water }\end{array}$ \\
\hline- & 1560 & 1560 & $v_{\text {as }} \mathrm{COO}^{-}$of Na-acrylate \\
\hline 1410 & 1406 & 1410 & $\begin{array}{c}v_{\mathrm{s}} \mathrm{COO}^{-} \text {of } \mathrm{Na} \text {-acrylate / } v \mathrm{CN} \text { of } \\
\text { acrylamide }\end{array}$ \\
\hline
\end{tabular}

total amount of monomers from PAm and PNaAc, assumed as $100 \%$. The band assigned to the carboxylate group at $1410 \mathrm{~cm}^{-1}$ was utilized as standard. To avoid difference in polymer concentration within the $\mathrm{KBr}$ pellet, relative absorbance was calculated in relation to the band at 2931-2944 $\mathrm{cm}^{-1}$, assigned to $\mathrm{CH}$ and $\mathrm{CH}_{2}$, taken as constant. The way in which the baseline of the two bands was drawn and absorbance was calculated is depicted in Figure 2.

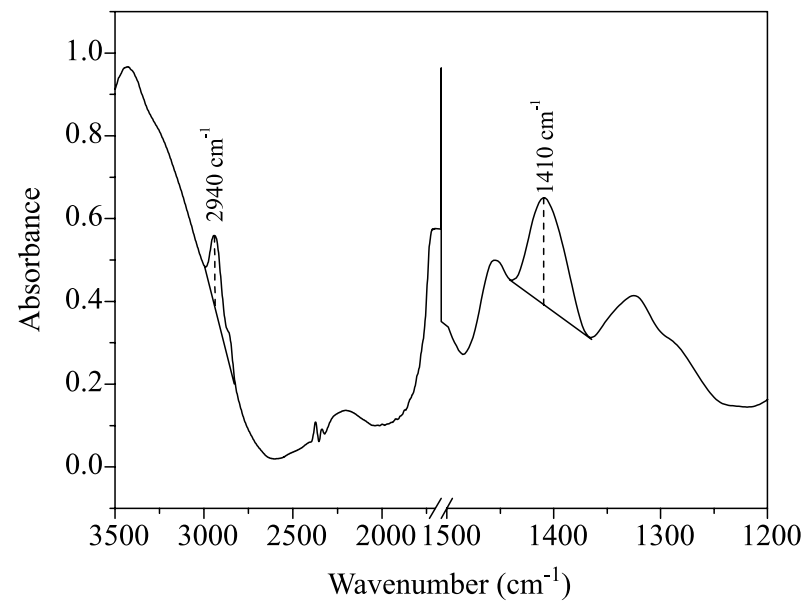

Figure 2. Bands and way utilized for the calculation of relative absorbance, $A_{\text {rel }}=A_{1410} / A_{2940}$

A straight line with a good linear correlation coefficient $(\mathrm{R}=$ 0.998) was obtained by plotting the acrylate content (Ac\%) versus relative absorbance $\left(\mathrm{A}_{\mathrm{rel}}=\mathrm{A}_{1410} / \mathrm{A}_{2940}\right)$ obtained from the mixture of $\mathrm{PAm}$ and $\mathrm{PNaAc}$ (Figure 3 ). The relative absorbance in zero acrylate content is due to the absorbance of the $\mathrm{CN}$ group of acrylamide. The equation obtained from a linear fit was:

$$
\mathrm{Ac} \%=-8.83+43.2 \mathrm{~A}_{\text {rel }}
$$

Real acrylate content $\left(\mathrm{Ac}_{\text {real }}\right.$, in mol\%) of hydrogels was calculated from $\mathrm{A}_{\text {rel }}$ and Equation 2. The correlation between the calculated and nominal acrylate content $\left(\mathrm{Ac}_{\text {nominal }}\right.$, in $\mathrm{mol} \%$ ) was demonstrated by the line shown in Figure 4. A good linear fit can be seen, with $\mathrm{R}$ equal to 0.9999. The equation is the following:

$$
\mathrm{Ac}_{\text {real }}=0.046+0.903 \mathrm{Ac}_{\text {nominal }}
$$

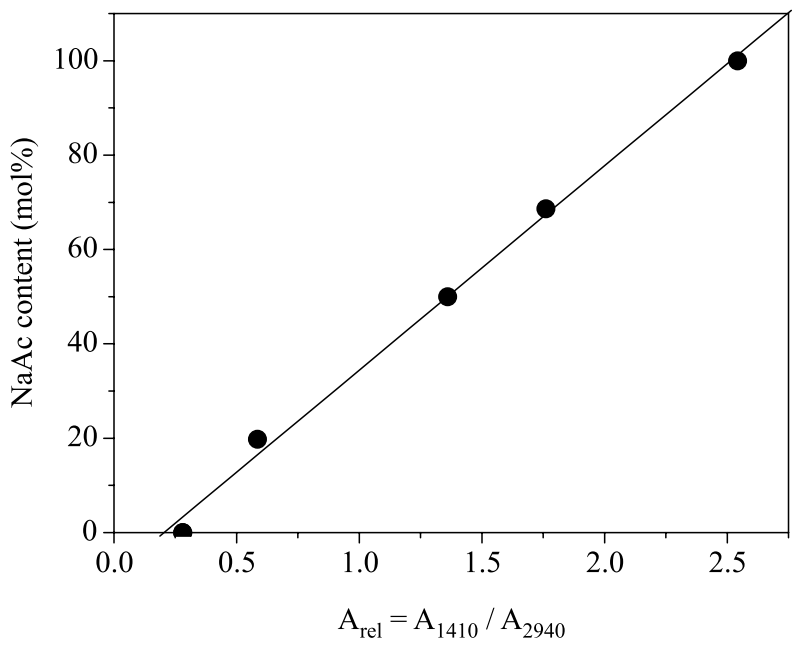

Figure 3. Calibration plot of acrylate content versus $A_{1410} A_{2940}$ obtained from mixture of homopolymers (polyacrylamide and sodium polyacrylate)

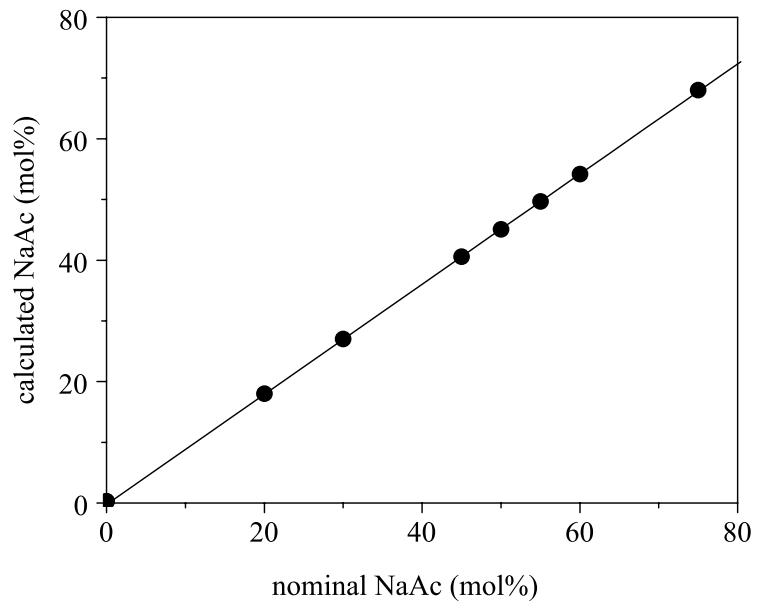

Figure 4. Calculation of real acrylate content of hydrogels of sodium acrylate and acrylamide based on FTIR

According to Durmaz and Okay, ${ }^{20}$ the linear dependence suggests that the monomeric units are randomly distributed in the polymeric chain. These authors found similar results with hydrogels based on acrylamide and 2-acrylamide-2-sodium methyl propanesulfonate.

The calculated acrylate content from a linear fit is shown in Table 3. All calculated values are lower than nominal levels. To compare results, the Gel (50/50) was immersed in acidified water $(\mathrm{pH} 2)$ until equilibrium was reached. The amount of sodium released was determined by atomic absorption spectroscopy. Sodium in water was $1.5 \mathrm{mg} / 100 \mathrm{~mL}$ and in $\mathrm{pH} 2.0$ was $5.52 \mathrm{mg} / 100 \mathrm{~mL}$. Taking into account that each acrylate group in the hydrogel is neutralized by one sodium ion, and that all $\mathrm{Na}^{+}$was substituted by $\mathrm{H}^{+}$, the released cation can be correlated with acrylate content. Based on this assumption the acrylate content is $45.3 \mathrm{~mol} \%$, very close to the $45.1 \mathrm{~mol} \%$ calculated by FTIR.

Comparing nominal with calculated acrylate content, a difference of $10 \pm 0.3 \%$ or less in calculated content was observed for all hydrogels. The difference is independent of NaAc content and can be correlated with monomer reactivity ratio. Chauhan and $\mathrm{Kumar}^{24}$ found that the reactivity of acrylic acid was greater than that of acrylamide in poly(HAc-co-Am) hydrogels. Hence, the probability of HAc entering into the copolymer chain is higher compared to Am. Therefore, even with the addition of an equal mole amount of co-monomer, the 
Table 3. Comparison between calculated and nominal acrylate content in hydrogels and their respective swelling in water

\begin{tabular}{ccc}
\hline \multicolumn{2}{c}{ Acrylate content $(\mathrm{mol} \%)$} & $\begin{array}{c}\mathrm{W}_{\mathrm{eq}} \\
\text { nominal }\end{array}$ \\
\cline { 1 - 2 } 20 & 17.9 & $144 \pm 2$ \\
30 & 27.0 & $161 \pm 2$ \\
45 & 40.6 & $169 \pm 2$ \\
50 & 45.1 & $172 \pm 1$ \\
55 & 49.6 & $172 \pm 1$ \\
60 & 54.2 & $173 \pm 2$ \\
75 & 67.8 & $189 \pm 4$ \\
\hline
\end{tabular}

hydrogel was richer in HAc. This result is contrary to that found in the present work, showing the hydrogel to be richer in acrylamide. However, sodium acrylate, instead of acrylic acid was employed. Sodium acrylate polymerizes less readily than acrylic acid, because ionized monomers react more slowly in the propagation step of polymerization. ${ }^{25}$ The results found for poly(NaAc-co-Am) hydrogels indicate that acrylamide is around $20 \%$ more reactive than $\mathrm{NaAc}$. As a consequence, reactivity seems to follow the order: acrylamide $>$ sodium acrylate $>$ acrylic acid.

\section{Swelling}

The effect of real acrylate content on equilibrium swelling can be seen in Table 3 . The PAm hydrogel ( $0 \mathrm{~mol} \%$ of NaAc) absorbed $12 \pm 1 \mathrm{~g}$ water/g gel, much lower than the hydrogel with $18 \%$ of $\mathrm{NaAc}$ $\left(\mathrm{W}_{\mathrm{eq}}=144 \pm 2 \mathrm{~g}\right.$ water/g gel $)$. At $74 \%$ of NaAc, the water absorption reached $189 \pm 4 \mathrm{~g}$ water/g gel. There is a substantial increment for the PNaAc, with $\mathrm{W}_{\mathrm{eq}}$ of $260 \mathrm{~g}$ water/g gel. At around $50 \%$ acrylate, an interesting effect was observed with a plateau between 40.6 and $54.2 \mathrm{~mol} \%$ of NaAc, equivalent to Gel (55/45) and Gel (40/60). The $\mathrm{W}_{\text {eq }}$ value was $171 \pm 2 \mathrm{~g}$ water/g gel. A similar effect was reported previously ${ }^{25}$ with mole fraction of acrylamide ranging from 0.4 to 0.6. Hydrogels with $18 \mathrm{~mol} \%$ or more of NaAc are superabsorbent.

\section{CONCLUSIONS}

A method for the calculation of acrylate content, based on absorbance at $1410 \mathrm{~cm}^{-1}\left(\mathrm{nCOO}^{-}\right)$and $2940 \mathrm{~cm}^{-1}\left(\mathrm{vCH}\right.$ and $\left.\mathrm{vCH}_{2}\right)$ by infrared spectroscopy, was proposed and tested for hydrogels prepared by free-radical crosslinking solution copolymerization of acrylamide and sodium acrylate using methylene bisacrylamide as the crosslinking agent. A straight line with a good linear correlation coefficient ( $\mathrm{R}=0.998$ ) was obtained by plotting acrylate content (Ac\%) versus relative absorbance $\left(\mathrm{A}_{\text {rel }}=\mathrm{A}_{1410} / \mathrm{A}_{2940}\right)$. Excellent linear correlation between calculated and nominal acrylate content was observed with $\mathrm{R}$ higher than 0.9999 . These results indicate that the proposed method is reliable and adequate for calculating acrylate content in hydrogels. An additional conclusion was based on the finding that calculated content of acrylate was consistently lower than the added content of acrylamide, with a difference of around $10 \%$ in all cases. Hence, acrylamide is around $20 \%$ more reactive than NaAc.

\section{ACKNOWLEDGEMENTS}

This work was supported by CT-Hidro, CNPq, FUNCAP and INCT-INOMAT.

\section{REFERENCES}

1. Zohuriaan-Mehr, M. J.; Kabiri, K.; Iran. Polym. J. 2008, 17, 451.

2. Fiumefreddo, A.; Utz, M.; Macromolecules 2010, 43, 5814.

3. Xie, J.; Liu, X.; Liang, J.; J. Appl. Polym. Sci. 2007, 106, 1606.

4. Bajpai, S. K.; Johnson, S.; J. Macromol. Sci. 2007, 44, 285.

5. Ray, D.; Mohapatra, D. K.; Mohapatra, R. K.; Mohanta, G. P.; Sahoo, P. K.; J. Biomater. Sci. Polym. Edn. 2008, 19, 1487.

6. Turan, E.; Çaykara, T.; J. Appl. Polym. Sci. 2007, 106, 2000.

7. Xie, J.; Liu, X.; Liang, J.; Luo, Y.; J. Appl. Polym. Sci. 2009, 112, 602.

8. Orozco-Guareño, E.; Santiago-Gutiérrez, F.; Morán-Quiroz, J. L.; Hernandez-Olmos, S. L.; Soto, V.; de la Cruz, W.; Manríquez, R.; Gomez-Salazar, S.; J. Colloid Interface Sci. 2010, 349, 583.

9. Şolpan, D.; Duran, S.; Torun, M.; Radiat. Phys. Chem. 2008, 77, 447.

10. Tomar, R. S.; Gupta, I.; Singhal, R.; Nagpal, A. K.; Des. Monom. Polym. 2007, 10, 49.

11. Zhang, Y.; Fan, L.; Cheng, L.; Zhang, L.; Chen, H.; Polym. Eng. Sci. 2009, 44, 264.

12. Tao, W.; Xiaoqinq, W.; Yi, Y.; Wenqionq, H.; Polym. Int. 2006, 55, 1413.

13. Candido, J. S.; Leitão, R. C. F.; Ricardo, N. M. P. S.; Feitosa, J. P. A.; Muniz, E. C.; Rodrigues, F. H. A.; J. Appl. Polym. Sci. 2012, 123, 879.

14. Sadegh, M.; Hosseinzadeh, H.; Turk. J. Chem. 2008, 32, 375.

15. Sadegh, M.; Hosseinzadeh, H.; J. Appl. Polym. Sci. 2008, 108, 1142.

16. Silva, D. A.; PhD Thesis, Federal University of Ceara, Brazil, 2006.

17. Guilherme, M. R.; Campese, G. M.; Radovanovic, E.; Rubira, A. F.; Feitosa, J. P. A.; Muniz, E. C.; Polymer 2005, 46, 7867.

18. Zhao, Q.; Sun, J.; Lin, Y.; Zhou, Q.; React. Funct. Polym. 2010, 70, 602.

19. Bhargava, R.; Wang, S. Q.; Koenig, J. L.; Adv. Polym. Sci. 2003,163, 137.

20. Durmaz, S.; Okay, O.; Polymer 2000, 41, 3693.

21. Okay, O.; Yilmaz, Y.; Kaya, D.; Keskinel, M.; Pekcan, Ö.; Polym. Bull. 1999, 43,425 .

22. Jeon, C. H.; Makhaeva, E. E.; Khokhlov, A. R.; Macromol. Chem. Phys. 1998, 199, 2665.

23. Silverstein, R. M.; Webster, F. X.; Spectrometric Identification of Organic Compounds, $6^{\text {th }}$ ed., Wiley: New York, 1998.

24. Chauhan, G. S.; Kumar, A.; J. Appl. Polym. Sci. 2008, 110, 3795.

25. Kiatkamjornwong, S.; Wongwatthanasatien, R.; Macromol. Symp. 2004, 207, 229. 